\title{
CORRECTION
}

https://doi.org/10.1038/s41586-018-0759-x

\section{Author Correction: Reassessing evidence of life in 3,700-million-year-old rocks of Greenland}

Abigail C. Allwood, Minik T. Rosing, David T. Flannery, Joel A. Hurowitz \& Christopher M. Heirwegh

Correction to: Nature https://doi.org/10.1038/s41586-018-0610-4, published online 17 October 2018.

In Extended Data Fig. 1 of this Letter, the map showed the location of our field work incorrectly. The location is: $49^{\circ} 48^{\prime} 15^{\prime \prime} \mathrm{W}, 65^{\circ} 10^{\prime} 45^{\prime \prime} \mathrm{N}$, and the figure has been corrected online. The original, incorrect Extended Data Fig. 1 is shown as Fig. 1 to this Amendment for transparency.
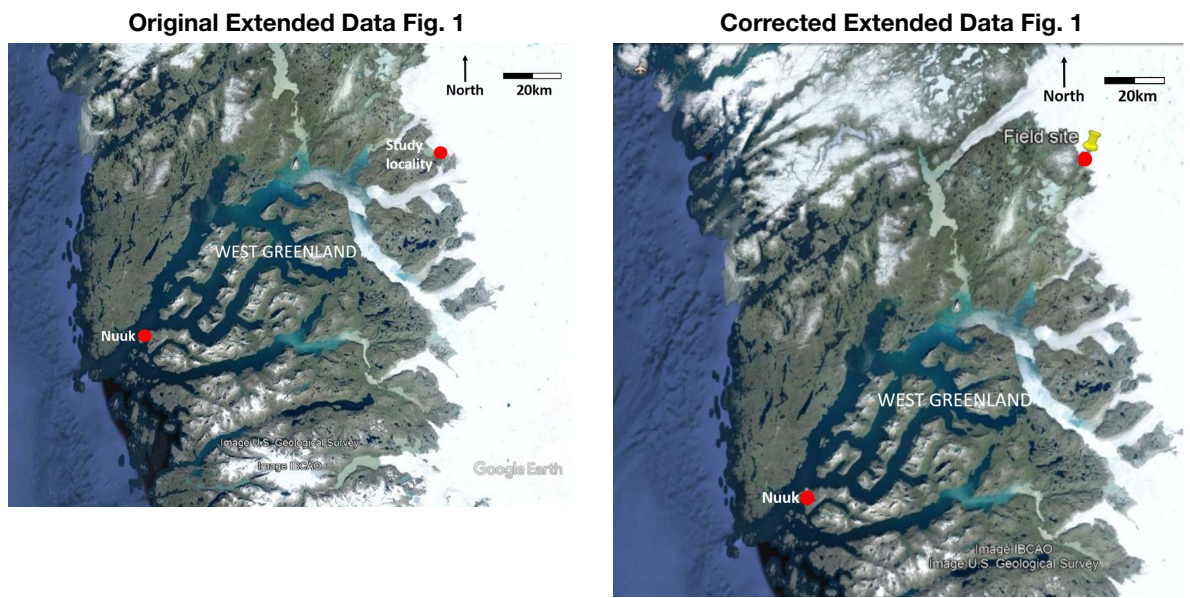

Fig. 1 This figure displays the corrected and the incorrect published Extended Data Fig. 1 of the original Letter. This figure depicts the incorrect published Extended Data Fig. 1 (left) and the corrected Extended Data Fig. 1 (right) of the original Letter, with the corrected field location site indicated. 